\title{
ENDOGENOUS PYROGEN/INTERLEUKIN-1 PRODUCTION IN AGED RATS
}

\author{
Carol A. Kauffman, M.D.* \\ Division Of Infectious Diseases, Department Of Internal Medicine, \\ Veterans Administration Medical Center, and University Of Michigan Medical School, \\ Ann Arbor, Michigan 48109
}

\begin{abstract}
The effect of aging on the ability of macrophages to produce endogenous pyrogen/interleukin-1 (EP/IL-1) was tested in 13 young adult (2-3 mo) and 13 aged (24-26 mo) Fischer rats using a febrile response assay. Peritoneal macrophages from aged rats produced EP/IL-1 as well as young adult rats. Decreased production of EP/IL-1 does not appear to explain the diminished febrile response seen in the elderly.
\end{abstract}

Key Words: endogenous pyrogen, interleukin-1, febrile response, macrophages, fever in aged rats

\section{INTRODUCTION}

CliniCal DATA suggest that elderly persons do not manifest as vigorous a febrile response as younger persons (Yoshikawa, 1983). We have used the Fischer 344 aged rat model to explore the effects of age on the febrile response. Previous experiments showed a diminished febrile response to endotoxin in aged rats, but only if they were kept in a cold environment (Tocco-Bradley, Kluger, and Kauffman, 1985). Further work revealed that the febrile response in aged rats was similar to that of young adult rats when given either intracerebroventricular or intravenous endogenous pyrogen/interleukin-1 (EP/IL-1), the protein responsible for the induction of fever (Tocco-Bradley, Singer, Kluger, and Kauffman, 1985).

Thus, it appeared that aging did not have adverse effects on the hypothalamus or on the peripheral thermoeffector mechanisms which respond to EP/IL-1. The current study assessed the effect of aging on one further aspect of the febrile response, the production of EP/IL-1 by macrophages.

\section{MATERIALS AND METHODS}

Fischer 344 male rats were housed in individual cages at $26^{\circ} \mathrm{C}$ in a 12 hour light/dark photoperiod and supplied with water and rodent chow ad libitum. EP/IL-1 production

\footnotetext{
*Correspondence and reprint requests to: Carol A. Kauffman, M.D., Veterans Administration Medical Center, Ann Arbor, MI 48105.

(Received 4 December 1985, Revised 22 January 1986, Accepted 30 January 1986)
} 
from peritoneal macrophages was studied in 13 young adult rats ( $2-3$ months old) and 13 aged rats (24-26 months old).

Peritoneal macrophages were elicited by intraperitoneal injection of $40 \mathrm{ml}$ of $0.2 \%$ shellfish glycogen (Sigma, Inc.; St. Louis, MO) 3 days prior to the experiment. Macrophages were obtained by lavage of the opened peritoneal cavity with Hanks' balanced salt solution (HBSS). The number of macrophages obtained per rat ranged between $2.1 \times 10^{7}$ and $4.3 \times 10^{7}$ in the elderly rats and between $1.1 \times 10^{7}$ and $3.5 \times 10^{7}$ in the young rats. Cells were centrifuged, washed twice with HBSS and resuspended in HBSS with $10 \%$ pooled human serum, at a concentration of $2.5 \times 10^{6}$ macrophages $/ \mathrm{ml}$. Macrophage preparations were stimulated for 1 hour at $37^{\circ} \mathrm{C}$ by mixing with heat-killed Staphylococcus epidermidis at a ratio of 20 bacteria/1 macrophage. Cells were then centrifuged, washed with HBSS and incubated for 18 hours in a $5 \% \mathrm{CO}_{2}$ atmosphere at $37^{\circ} \mathrm{C}$. Following incubation, the supernatants were collected and stored at $-20^{\circ} \mathrm{C}$ until assayed within the next week.

The assay used for EP/IL-1 was production of fever in healthy 4 month old Fischer 344 male rats. To measure body temperature, each rat was implanted 5 days earlier with an intraperitoneal bio-telemetry device (Mini-Mitter, Inc.; Sun River, OR) as described previously (Tocco-Bradley, Kluger, and Kauffman, 1985). Initial dose-response studies showed that a consistent and reproducible temperature response in the assay rats was obtained using $2 \mathrm{ml}$ of EP/IL-1 from each donor rat (amount derived from $5 \times 10^{6}$ macrophages). Therefore, $2 \mathrm{ml}$ of EP/IL-1 from each young adult or aged rat was injected intraperitoneally into each of 3 different recipient rats kept at $26^{\circ} \mathrm{C}$, the rat's thermoneutral zone. Body temperature was recorded every 30 minutes beginning $1 / 2$ hour prior to injection and continuing for 6 hours after injection. On each day an assay was performed, one-half of the rats received EP/IL-1 and one-half received HBSS, as a control.

Results were expressed as change in temperature from baseline at each time point. Mean values \pm S.E.M. for each of the 3 rats used for the assay of each sample of EP/IL-1 were obtained for each time point. Differences between the febrile responses to EP/IL-1 obtained from aged and young adult rats and between the febrile responses to EP/IL-1 and HBSS were compared using the Student $t$-test.

\section{RESULTS}

No differences were noted in the febrile responses shown by rats injected with EP/IL-1 made from macrophages of aged rats or of young adult rats (Fig. 1). The same height of fever and the same time course of the febrile response were found. Mean temperatures over six hours $\left(\Delta \mathrm{T}_{6}\right)$ were similar for EP/IL-1 from aged rats $\left(\Delta \mathrm{T}_{6}=0.44 \pm 0.05^{\circ} \mathrm{C}\right)$ and from young adult rats $\left(\Delta \mathrm{T}_{6}=0.43 \pm 0.05^{\circ} \mathrm{C}\right)$. Fevers produced by EP/IL-1 from both aged and young adult rats were significantly different from the response to $\operatorname{HBSS}(p<$ $0.001)$.

\section{DISCUSSION}

Few studies have attempted to discover the cause for the decreased febrile response described in the elderly. We have used the Fischer 344 rat as a model of aging in order to explore the effect of age alone on the ability to generate a febrile response. The current data show that macrophages from aged rats produce EP/IL-1 as well as macrophages from young adult rats, thus confirming our initial studies with human monocytes in which ag- 


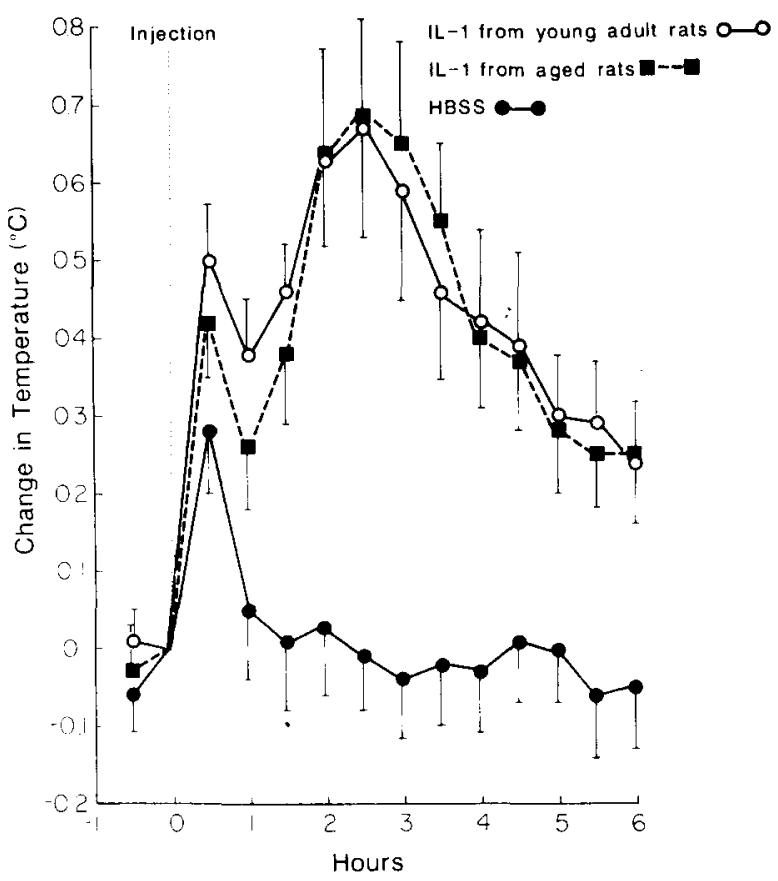

FIG. 1. Change in body temperature of rats given intraperitoneal injections of EP/IL-1 produced by peritoneal macrophages of aged rats or young adult rats or HBSS. Differences between the febrile responses to aged rat EP/IL-1 and young rat EP/IL-1 were not statistically significant. Differences between the responses to aged EP/IL-1 and HBSS and young adult EP/IL-1 and HBSS were significant $(p<0.001)$.

ing alone did not decrease the ability of monocytes to produce EP/IL-1 (Jones, Kauffman, Bergman, Hayes, Kluger, and Cannon, 1984). These results differ from those described by Bruley-Rosset and Vergnon in mice, but their study used thymocyte proliferation rather than febrile response as the assay for EP/IL-1 and endotoxin in vitro as the stimulus for IL-1 production (Bruley-Rosset and Vergnon, 1984). However, Rosenberg et al., using the thymocyte proliferation assay and endotoxin as the stimulus for IL-1 production in rats, obtained results similar to ours; they found that aging did not decrease EP/IL-1 production (Rosenberg, Gilman, and Feldman, 1983).

Using the Fischer rat, we have previously shown that aging does not influence the ability to respond to EP/IL-1 injected either directly into the cerebral ventricles or systemically (Tocco-Bradley, Singer, Kluger, and Kauffman, 1985). Thus, it would appear that all facets of the febrile response when tested individually function normally in the aged rat. The diminished response to endotoxin in the cold in aged rats might be related to effects of endotoxin directly on blood vessels in aging animals rather than to an effect on the EP/IL-1 mediated febrile response (Tocco-Bradley, Kluger, and Kauffman, 1985).

This study, as well as that carried out in humans, lends support to the concept that aging, per se, may not lead to a defect in the febrile response, but that other events which are common in the aged, such as malnutrition and chronic disease may be more important in diminishing the febrile response (Bienia, Ratcliff, Barbour, and Kummer, 1982; Keenan, Moldwawer, Yang, Kawamura, Blackburn, and Bistrian, 1982). 
Acknowledgments - This study was supported by the Veterans Administration Research Service.

\section{REFERENCES}

BIENIA, R.; RATCLIFF, S.; BARBOUR, G.L.; KUMMER, M. (1982) J. Am. Geriatr. Soc. 30: 433.

BRULEY-ROSSET, M.; and VERGNON, I. (1984) Mech. Ageing Dev. 24: 247.

JONES, P.G.; KAUFFMAN, C.A.; BERGMAN, A.G.; HAYES, C.M.; KLUGER, M.J.; CANNON, J.G. (1984) Gerontology 30: 182.

KEENAN, R.A.; MOLDAWER, L.L.; YANG, R.D.; KAWAMURA, I.; BLACKBURN, G.L.; BISTRIAN, B. (1982) J. Lab. Clin. Med. 100: 844.

ROSENBERG, J.S.; GILMAN, S.C.; FELDMAN; J.D. (1983) J. Immunol. 130: 1754.

TOCCO-BRADLEY, R.; KLUGER, M.J.; KAUFFMAN, C.A. (1985) Infect. Immun. 47: 106.

TOCCO-BRADLEY, R.; SINGER, R.; KLUGER, M.J.; KAUFFMAN, C.A. (1985) Gerontology 31: 349.

YOSHIKAWA, T.T. (1983) J. Am. Geriatr. Soc. 31: 34. 